\title{
Macula Densa Arginine Delivery and Uptake in the Rat Regulates Glomerular Capillary Pressure \\ Effects of Salt Intake
}

William J. Welch and Christopher S. Wilcox

Division of Nephrology and Hypertension, Georgetown University Medical Center, Washington, DC 20007

\begin{abstract}
These studies tested the hypothesis that delivery and/or cellular uptake of L-arginine limits macula densa nitric oxide generation and actions on tubuloglomerular feedback (TGF) during salt restriction. Maximal TGF responses were assessed from reductions in proximal stop flow pressure during loop of Henle (LH) perfusion at $40 \mathrm{nl} / \mathrm{min}$ with artificial tubular fluid containing vehicles or drugs. Orthograde LH perfusion of L-arginine $\left(10^{-3} \mathrm{M}\right)$ reduced maximal TGF significantly in rats adapted to low salt (LS: 7.9 $\pm 0.4-6.3 \pm 0.4$ $\mathrm{mmHg} ; P<0.05$ ), but not high salt (HS: $5.8 \pm 0.3-5.9 \pm 0.3$; NS). The effects were stereospecific and prevented by coperfusion with $N^{\mathrm{G}}$-methyl-L-arginine. Microperfusion of L-arginine $\left(10^{-3} \mathrm{M}\right)$ into the peritubular capillaries reduced the maximum TGF response more in nephrons of LS than HS rats ( $\Delta$ TGF: LS, $32 \pm 6$ vs. HS, $13 \pm 4 \% ; P<0.05$ ) and restored a TGF response to luminal perfusion of $N^{\mathrm{G}}$-methyl-L-arginine in LS rats. Coperfusion of nephrons with excess L-lysine or L-homoarginine, which compete with L-arginine for system $\mathrm{y}^{+}$transport, blocked the fall in proximal stopflow pressure produced by orthograde $\mathrm{LH}$ perfusion of L-arginine in LS rats. Reabsorption of $\left[{ }^{3} \mathrm{H}\right]$ arginine by the perfused loop segment was similar in LS $(93 \pm 2 \%)$ and HS (94 $\pm 1 \%)$ rats. Coperfusion with excess L-arginine, L-lysine, or L-homoarginine, however, reduced $\left[{ }^{3} \mathrm{H}\right]$ arginine reabsorption significantly $(P<0.05)$ more in HS rats than in LS rats. In conclusion, blunting of maximal TGF responses in salt-restricted rats by nephron-derived NO is limited by L-arginine availability and cellular uptake via system $\mathrm{y}^{+}$. (J. Clin. Invest. 1997. 100:2235-2242.) Key words: nitric oxide - system $y^{+}$transport • nitric oxide synthase • tubuloglomerular feedback
\end{abstract}

\section{Introduction}

The tubuloglomerular feedback (TGF) ${ }^{1}$ response is activated by $\mathrm{NaCl}$ reabsorption at the macula densa (MD) segment that increases afferent arteriolar tone and reduces glomerular capillary pressure $\left(\mathrm{P}_{\mathrm{GC}}\right)$ and GFR (1). A constitutive, neuronal ni-

Address correspondence to Dr. Christopher S. Wilcox, Division of Nephrology and Hypertension, Georgetown University Medical Center, 3800 Reservoir Road, NW PHC F6003, Washington, DC 20007. Phone: 202-687-8539; FAX: 202-687-7893.

Received for publication 20 February 1997 and accepted in revised form 12 September 1997.

J. Clin. Invest.

(C) The American Society for Clinical Investigation, Inc. 0021-9738/97/11/2235/08 \$2.00

Volume 100, Number 9, November 1997, 2235-2242

http://www.jci.org tric oxide synthase (NOS) isoform is located in the MD (2-4) where nitric oxide (NO) is generated from L-arginine during solute reabsorption, and can dampen TGF responses $(2,5,6)$. Our previous studies, however, showed that perfusion of $N^{\mathrm{G}}$-methyl-L-arginine (L-NMA) into the loop of Henle (LH) and MD to block NOS potentiated TGF responses of rats receiving a high salt (HS) intake, but was ineffective in rats on a low salt (LS) intake $(5,7)$. This result suggests that nephronderived NO may participate in adapting TGF responses to salt intake. The mechanism whereby salt restriction prevents the nephron response to NOS inhibition, however, is currently unclear. It is probably not due to a decrease in NOS expression since immunocytochemical studies have shown that dietary salt restriction enhances the expression of NOS in the MD $(8$, 9). Moreover, reverse transcription-PCR studies in microdissected vascular poles with attached MD segments have shown that salt restriction enhances the abundance of mRNA transcription for the nNOS gene (10). Since recent studies have shown that MD perfusions of L-arginine can stimulate renin release (11) and dampen TGF responses (6), we tested the role of L-arginine delivery and cellular uptake in adapting MD NO generation to changes in salt intake.

Infusions of $\mathrm{L}$-arginine cause renal vasodilation. This effect is stereospecific and is blocked by nitro-L-arginine methyl ester (L-NAME), which indicates that it is dependent on NOS (12). Since the renal circulation is more sensitive to the vasodilator action of L-arginine during salt restriction (12), and the plasma levels of L-arginine are reduced in salt-restricted rats (13), the availability of L-arginine may be limiting for NO generation in the kidney of salt-restricted rats. Therefore, we tested the hypothesis that NO generation in the MD is limited during dietary salt restriction because of a reduced availability or uptake of L-arginine. This hypothesis was tested by comparing dynamic changes in glomerular capillary pressure during microperfusion of L-arginine into the LH, MD segment, and peritubular capillaries of rats adapted to HS or LS intakes. To determine the mechanism of the different responses to L-arginine with salt intake, we performed additional series of experiments. The ability of L-arginine delivered locally into the peritubular capillary to restore a $\mathrm{P}_{\mathrm{GC}}$ response to luminal perfusion of L-NMA in LS rats was tested to assess the role of decreased arginine availability in limiting juxtaglomerular apparatus (JGA) NO generation during salt restriction. The effect of salt intake on arginine transport was tested in two subsequent experi-

1. Abbreviations used in this paper: $\mathrm{A}_{1}$ Ado $\mathrm{R}$, adenosine type 1 receptor; ADMA, asymmetric dimethylarginine; ATF, artificial tubular fluid; HS, high salt intake; JGA, juxtaglomerular apparatus; L-NAME, $N^{\mathrm{G}}$-methyl-L-arginine; LH, loop of Henle; LS, low salt intake; MAP, mean arterial pressure; $\mathrm{MD}$, macula densa; $\mathrm{NO}$, nitric oxide; $\mathrm{P}_{\mathrm{GC}}$, glomerular capillary hydraulic pressure; PSF, proximal stop flow pressure; PTC, peritubular capillary; TGF, tubuloglomerular feedback. 
ments. L-lysine and L-homoarginine compete with L-arginine for sodium-independent system $\mathrm{y}^{+}$transport in blood vessels (14), endothelial cells (15), and neuronal cells (16). Therefore, L-lysine or L-homoarginine were coperfused with L-arginine to investigate whether the response to arginine required transport via this pathway.

Previous studies have shown carrier-mediated L-arginine transport in the loop of Henle $(17,18)$. The effect of salt intake and system $\mathrm{y}^{+}$inhibitors on L-arginine absorption from the perfused loop segment was studied directly using $\left[{ }^{3} \mathrm{H}\right] \mathrm{L}-$ arginine perfused from the late proximal tubule, and was sampled at the early distal tubule.

\section{Methods}

\section{Animal preparation}

Male Sprague-Dawley rats (225-325 g) were maintained for 7-10 d on diets with a LS (Na content $0.03 \mathrm{~g} / 100 \mathrm{~g}$ of NaCl) or HS (Na content $2.4 \mathrm{~g} / 100 \mathrm{~g}$ ) content. The LS and HS diets were identical except for $\mathrm{NaCl}$ content (Teklad Premier Laboratory Diets, Madison, WI). The LS diet is sufficient for normal growth during this period. Rats were prepared for micropuncture experiments under thiobarbital anesthesia (Inactin $100 \mathrm{mg} / \mathrm{kg}$; Research Biochemicals, Inc., Natick, MA). Catheters were placed in a jugular vein for fluid infusion, in the femoral artery for recording of mean arterial pressure (MAP), and in the bladder. A tracheostomy tube was inserted to allow for unrestricted respiration. The left kidney was exposed by a flank incision, cleaned of connective tissue, and maintained in a stable Lucite cup. The kidney was bathed with $0.154 \mathrm{M} \mathrm{NaCl}$ maintained at $37^{\circ} \mathrm{C}$, and was prepared for micropuncture and microperfusion as described previously (19). After surgery, animals were infused with a maintenance solution containing $2.5 \%$ dextrose, $0.077 \mathrm{M} \mathrm{NaCl}$, and $1 \%$ albumin at $1.5 \mathrm{ml} / \mathrm{h}$ to maintain a euvolemic state. Micropuncture studies were begun after a 60 -min stabilization period.

For orthograde microperfusion of the LH, a micropipette (6-8 $\mu \mathrm{m}$ OD) containing artificial tubular fluid (ATF) with FD\&C no. 6 dye was inserted into a late proximal tubule (19). Injections of the colored ATF identified the nephron and the direction of flow. An immobile bone wax block was inserted into this micropuncture site by a micropipette $(10-15 \mu \mathrm{m})$ connected to a hydraulic drive (Trent Wells, La Jolla, CA) to stop the flow of tubular fluid. A perfusion micropipette $(6-8 \mu \mathrm{m})$ containing ATF with test compounds or vehicle was inserted into the late proximal tubule downstream from the wax block and connected to a nanoliter perfusion pump (World Precision Instruments, Inc., Sarasota, FL). A pressure micropipette $(1-2 \mu \mathrm{m})$ was inserted into the proximal tubule upstream from the wax block to measure proximal stop flow pressure (PSF). Changes in PSF are an index of changes in $\mathrm{P}_{\mathrm{GC}}$. Measurements were made during zero loop perfusion and during perfusion with ATF with a composition similar to late proximal tubular fluid at $40 \mathrm{nl} / \mathrm{min}$ (corresponding to maximal activation of TGF responses).

For retrograde microperfusion into the MD segment, an early distal tubule was identified, a wax block was inserted, and a perfusion pipette was placed upstream. The late proximal tubule of that nephron was vented. The MD was perfused with an ATF whose composition was similar to early distal tubular fluid (19) at zero and $20 \mathrm{nl} / \mathrm{min}$, which produced a maximal TGF response.

For peritubular capillary (PTC) microperfusion, a nephron was prepared as described above for orthograde microperfusion. Another microperfusion pipette $(8 \mu \mathrm{m}$ OD) was inserted into an adjacent welling point efferent arteriole supplying the peritubular capillaries. The perfusion pipette was filled with artificial plasma (AP) (19), stained with FD\&C no. 6 dye, and perfused at $15 \mathrm{nl} / \mathrm{min}$ (corresponding to $\sim 10-15 \%$ of nephron plasma flow rate). The nephron region was considered perfused if adjacent vessels were colored by the perfusate. The maximal TGF response in the target nephron was as- sessed from changes in PSF during orthograde perfusion of ATF containing vehicle or drugs at $40 \mathrm{nl} / \mathrm{min}$ as described above.

\section{Protocols}

Series 1. The aim was to study the effects of local microperfusion of L-arginine, delivered into the LH by either the orthograde or retrograde routes, on maximal TGF responses. Perfusion micropipettes were filled with ATF + vehicle or ATF + L-arginine $\left(10^{-3} \mathrm{M}\right)$. This dose of L-arginine was chosen after preliminary dose-finding studies showed it to produce a maximal response. The LH were perfused orthogradely in random order with ATF containing the vehicle or L-arginine. Paired observations were made in each nephron comparing the response to perfusion of L-arginine or vehicle. PSF was measured during zero perfusion, and again at $40 \mathrm{nl} / \mathrm{min}$ with ATF. 1-3 nephrons were perfused in each rat. Studies of orthograde perfusion were undertaken in groups of rats equilibrated to low salt $(n=12)$ or high salt $(n=11)$ diets for 8-10 days before testing.

Retrograde microperfusion studies were undertaken in the light of results from subsequent protocols that demonstrated significant reabsorption of arginine from the perfused LH. We deliberately selected a high and maximally effective concentration of $\mathrm{L}$-arginine for the orthograde tubular perfusions so that L-arginine could be delivered in maximally effective concentrations to the MD. It was possible, however, that the effects of salt intake on the PSF response to orthograde perfusion of L-arginine from the proximal tubule could have been secondary to differential uptake of L-arginine in the loop, leading to differential rates of arginine delivery to the MD. Therefore, the aim of these studies was to investigate the effects of dietary salt intake on the $\mathrm{P}_{\mathrm{GC}}$ response to retrograde microperfusions of L-arginine from the early distal tubule directly into the MD segment. For this series, groups of LS $(n=6)$ and HS $(n=6)$ rats were prepared, and PSF responses were recorded in each nephron during zero microperfusion, and during microperfusion at $20 \mathrm{nl} / \mathrm{min}$ with ATF + vehicle and ATF $+\mathrm{L}$-arginine $\left(10^{-3} \mathrm{M}\right)$ from the early distal tubule into the MD segment of vented nephrons.

Series 2. The aim was to study whether the blunting of TGF responses in LS rats by luminally delivered L-arginine depends on NOS. First, nephrons $(n=11)$ of LS rats were microperfused with ATF + vehicle and ATF + D-arginine $\left(10^{-3} \mathrm{M}\right)$ that is not a substrate for this enzyme. Second, nephrons $(n=10)$ were microperfused with ATF + vehicle, ATF + L-NMA $\left(10^{-3} \mathrm{M}\right)$, or ATF + L-arginine $\left(10^{-3} \mathrm{M}\right)+$ L-NMA $\left(10^{-3} \mathrm{M}\right)$. Since the initial studies demonstrated consistent responses to L-arginine in rats adapted to a low salt intake, these studies were undertaken in LS rats.

Series 3. The aim was to study the effects of L-arginine microperfused into the PTC on maximal TGF responses and the role of salt intake. Rats were adapted to a low salt $(n=12)$ or high salt $(n=12)$ intake. The test nephron was perfused orthogradely at 0 and $40 \mathrm{nl} / \mathrm{min}$ with ATF + vehicle. Thereafter, a micropipette was inserted into the efferent arteriole for microperfusion of $\mathrm{L}$-arginine (at $10^{-4}$ or $10^{-3} \mathrm{M}$ ) in AP (19) containing FD\&C no. 6 dye at $15 \mathrm{nl} / \mathrm{min}$ into blood supplying the PTC. When a stable PTC perfusion had been achieved, as judged by the presence of the green perfusate in the peritubular capillaries around the test nephron, the PSF response to orthograde microperfusion of the $\mathrm{LH}$ at 0 and $40 \mathrm{nl} / \mathrm{min}$ with ATF + vehicle was reassessed. In previous studies, we had found that microperfusion of the PTC with artificial plasma at $20 \mathrm{nl} / \mathrm{min}$ did not alter TGF responses of the test nephron (19). Therefore, additional control studies with vehicle-perfused PTC were not undertaken. The lower concentration of L-arginine was selected to approximately restore the concentration of L-arginine measured previously in LS rats to the level in HS rats (13).

Additional studies were undertaken to test the hypothesis that the local L-arginine concentration in the PTC plasma surrounding the JGA limited NO generation selectively in LS rats, as indexed by their response to NOS blockade with luminal L-NMA. Accordingly, the change in PSF was recorded in each nephron during orthograde perfusion of ATF and ATF + L-NMA $\left(10^{-3} \mathrm{M}\right)$. Thereafter, the PTC were perfused with L-arginine $\left(10^{-4} \mathrm{M}\right)$ in $\mathrm{AP}$ at $15 \mathrm{nl} / \mathrm{min}$ and, after $1 \mathrm{~min}$, 
with the peritubular capillary perfusion continuing, the responses to luminal perfusions with ATF and ATF + L-NMA were repeated.

The results of these protocols demonstrated that peritubular capillary perfusion of L-arginine blunted TGF to a greater extent in LS than HS rats. To test the selectivity of this effect of salt intake on the response to L-arginine, the TGF response of a further series of LS $(n=6)$ and HS $(n=6)$ rats were studied during peritubular capillary perfusion of 1,3-dipropyl-8-(2-[5,6-epoxy]norbornyl)xanthine or CVT124. CVT-124 is a highly selective adenosine type $1\left(\mathrm{~A}_{1} \mathrm{AdoR}\right)$ antagonist (20) that blunts TGF (21) and vasodilates the afferent arteriole by an NO-independent mechanism (22). The PSF response to orthograde perfusion of the LH with ATF at $40 \mathrm{nl} / \mathrm{min}$ was assessed before and during peritubular capillary perfusion of CVT- $124\left(10^{-3} \mathrm{M}\right.$ in AP).

Series 4. The aim was to investigate whether any effects of luminally perfused L-arginine on PSF depend on cellular uptake by system $\mathrm{y}^{+}$. Groups of rats were adapted to a HS or LS diet. Nephrons were microperfused at $40 \mathrm{nl} / \mathrm{min}$ with $\mathrm{ATF}+$ vehicle, ATF + L-arginine $\left(10^{-3} \mathrm{M}\right)$ and, for series $4 \mathrm{~A}, \mathrm{ATF}+\mathrm{L}$-lysine $\left(2 \times 10^{-3} \mathrm{M}\right)$ or ATF + L-arginine $\left(10^{-3} \mathrm{M}\right)+$ L-lysine $\left(2 \times 10^{-3} \mathrm{M}\right)$ in random order, and PSF was recorded. A second set of nephrons from HS and LS rats (series 4B) were perfused similarly but with L-homoarginine $(2 \times$ $10^{-3} \mathrm{M}$ ) in place of L-lysine. L-lysine and L-homoarginine were selected as inhibitors of system $\mathrm{y}^{+}$transport (14-16).

Series 5. The aim was to investigate the effects of salt intake on absorption of $\left[{ }^{3} \mathrm{H}\right] \mathrm{L}$-arginine from perfused $\mathrm{LH}$ via system $\mathrm{y}^{+}$. A perfusion micropipette was inserted into the late proximal tubule, and a collection micropipette was inserted into the early distal tubule of the nephron upstream from an oil block of rats adapted to a LS $(n=$ $12)$ or HS $(n=12)$ intake. Perfusion solutions contained $\left[{ }^{3} \mathrm{H}\right] \mathrm{L}-$ arginine (15 cpm/nl; Amersham Corp., Arlington Heights, IL) and $\left[{ }^{14} \mathrm{C}\right]$ inulin $(5 \mathrm{cpm} / \mathrm{nl}$; ICN Biomedicals Inc., Irvine, CA) as a recollection marker. Nephrons were perfused in random order with $\mathrm{ATF}+$ vehicle, ATF + L-arginine $\left(10^{-3} \mathrm{M}\right), \mathrm{ATF}+\mathrm{L}$-lysine $\left(10^{-3} \mathrm{M}\right)$, ATF + L-homoarginine $\left(10^{-3} \mathrm{M}\right)$, or ATF + L-glycine $\left(10^{-3} \mathrm{M}\right)$. Glycine is not transported by system $\mathrm{y}^{+}$and was used as a control. Precisely timed orthograde perfusions were undertaken for $4 \mathrm{~min}$ at 20 $\mathrm{nl} / \mathrm{min}$. The microperfusion pump was calibrated regularly. In all studies, the $\left[{ }^{14} \mathrm{C}\right]$ inulin recovery was within the range of $90-110 \%$. The rate of $\left[{ }^{3} \mathrm{H}\right] \mathrm{L}$-arginine absorption from the perfused loop was calculated from the rates of perfusion and collection, corrected for $\left[{ }^{14} \mathrm{C}\right]$ inulin recovery.

\section{Analysis of results}

The PSF during zero LH perfusion was constant between protocols, and was unaffected by dietary salt intake (LS: $36.3 \pm 0.5$ vs. HS: $37.0 \pm 0.6$ $\mathrm{mmHg}$; NS). Therefore, the results are presented as changes in PSF during $\mathrm{LH}$ perfusion at $40 \mathrm{nl} / \mathrm{min}$, compared to values obtained during zero LH perfusion.

\section{Statistics}

Results are presented as mean \pm SEM values. ANOVA was used to assess the effects of the interventions and of salt intake. Post hoc test- ing, when appropriate, was made by Dunnett's test. Statistical significance was considered at $P<0.05$.

\section{Results}

As shown in Table I, there were no differences among the groups of LH or HS rats for body weight, experimental kidney weight, or MAP. The heart rate (HR) was slightly higher in LS rats. Rats of groups 1-5 had measurements of PSF during loop perfusion with ATF. In these groups, there were no significant effects of salt intake on PSF measured during zero perfusion. Increasing orthograde perfusions of ATF from 0 to $40 \mathrm{nl} / \mathrm{min}$ produced larger reductions in PSF in LS when compared with HS rats.

As depicted in Fig. $1 A$, the addition of L-arginine to the orthograde $\mathrm{LH}$ perfusate in rats of series 1 blunted the fall in PSF in nephrons of LS rats $(8.2 \pm 0.4-6.1 \pm 0.4 \mathrm{mmHg} ; P<$ 0.01 ) but had no significant effect in nephrons of HS rats (5.8 $\pm 0.3-5.9 \pm 0.3 \mathrm{mmHg}$; NS).

For the second set of studies, ATF was perfused retrogradely into the MD segment at $20 \mathrm{nl} / \mathrm{min}$. Again, as shown in Fig. $1 B$, there was a significantly stronger PSF response to $\mathrm{ATF}+$ vehicle in LS when compared with HS rats (LS: $8.3 \pm 0.4 ; n=16$, vs. HS: $5.8 \pm 0.3 \mathrm{mmHg} ; n=7 ; P<0.005)$. Addition of $\mathrm{L}$-arginine to the perfusate of LS rats again blunted the response $(8.3 \pm 0.4-7.1 \pm 0.4 \mathrm{mmHg} ; n=16 ; P<0.05)$, whereas L-arginine did not affect the response in HS rat nephrons $(5.8 \pm 0.3-6.1 \pm 0.4 \mathrm{mmHg} ; n=7$; NS). The blunting of TGF by L-arginine in LS rat nephrons was not significantly different when perfused orthogradely ( $\triangle \mathrm{PSF}: 1.8 \pm 0.6 \mathrm{mmHg}$ ) or retrogradely ( $\triangle \mathrm{PSF}: 1.0 \pm 0.4 \mathrm{mmHg}$ ). We conclude that luminal L-arginine blunts maximal TGF responses, but that this effect is prevented by salt loading.

For series 2, groups of LS rats were selected to test the role of NOS in the response to luminal L-arginine since consistent responses to L-arginine were seen in this group. As shown in Fig. 2, unlike L-arginine, orthograde perfusion of D-arginine in ATF into the loop segment did not significantly alter maximal TGF responses (vehicle: $8.2 \pm 0.4$ vs. D-arginine: $8.6 \pm 0.5$ $\mathrm{mmHg} ; n=8$; NS). As in previous studies (5), microperfusion of L-NMA $\left(10^{-3} \mathrm{M}\right)$ in ATF did not alter maximal TGF responses of these LS rats. Coperfusion of L-NMA orthogradely into the LH or into the peritubular capillaries, however, prevented the response to L-arginine perfused orthogradely into the LH. We conclude that the response to luminal L-arginine is stereospecific, and can be blunted by luminal or PTC delivery of L-NMA; presumably it depends on NOS.

Table I. Body and Kidney Weights, MAP, HR, and PSF During Changes in LH Perfusion: Effects of Salt Intake

\begin{tabular}{|c|c|c|c|c|c|c|c|}
\hline & \multirow[b]{2}{*}{ Body wt } & \multirow[b]{2}{*}{ Kidney wt } & \multirow[b]{2}{*}{ MAP } & \multirow[b]{2}{*}{ HR } & \multicolumn{3}{|c|}{ PSF (mmHg) during LH perfusion (nl/min) at: } \\
\hline & & & & & 0 & 40 & Difference \\
\hline & $g$ & $g$ & $m m H g$ & $\min ^{-1}$ & & & \\
\hline Low salt $(n=32)$ & $281 \pm 6$ & $1.09 \pm 0.04$ & $119 \pm 4$ & $393 \pm 6$ & $36.3 \pm 0.5$ & $28.1 \pm 0.6$ & $-8.2 \pm 0.4$ \\
\hline High salt $(n=27)$ & $293 \pm 10$ & $1.16 \pm 0.05$ & $113 \pm 3$ & $372 \pm 10$ & $37.0 \pm 0.6$ & $31.0 \pm 0.5$ & $-6.0 \pm 0.4$ \\
\hline \multicolumn{8}{|l|}{ Effects of salt intake } \\
\hline$P$ value & NS & NS & NS & $<0.05$ & NS & $<0.001$ & $<0.001$ \\
\hline
\end{tabular}

Mean \pm SEM values $(n=$ number of rats). The effects of salt intake were assessed by ANOVA. 

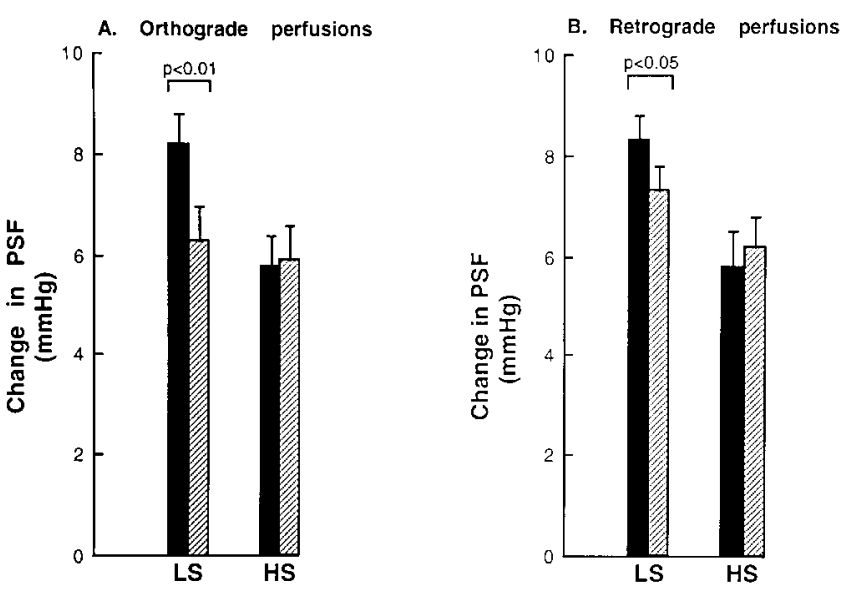

Figure 1. (A) Maximal tubuloglomerular feedback responses as assessed from changes in PSF during orthograde loop perfusion with ATF at 0 and $40 \mathrm{nl} / \mathrm{min}$ in low $(n=11)$ and high $(n=22)$ salt rat nephrons. Studies were undertaken with loop perfusion of ATF + vehicle (solid bars) and ATF + L-arginine $\left(10^{-3} \mathrm{M}\right.$; cross-hatched bars). $(B)$ Similar studies undertaken during retrograde perfusions of $\mathrm{ATF}+$ vehicle or ATF + L-arginine into low $(n=16)$ and high $(n=$ 7) salt rat nephrons.

For series 3, PTC delivery of L-arginine at the lower concentration of $10^{-4} \mathrm{M}$ reduced the maximal PSF responses to orthograde microperfusion of ATF into the LH of nephrons of LS rats ( $\triangle \mathrm{PSF}$, before: $9.2 \pm 0.5$ vs. during L-arginine: $6.5 \pm 0.8$ $\mathrm{mmHg} ; n=11 ; P<0.005)$ but had no significant effect on the

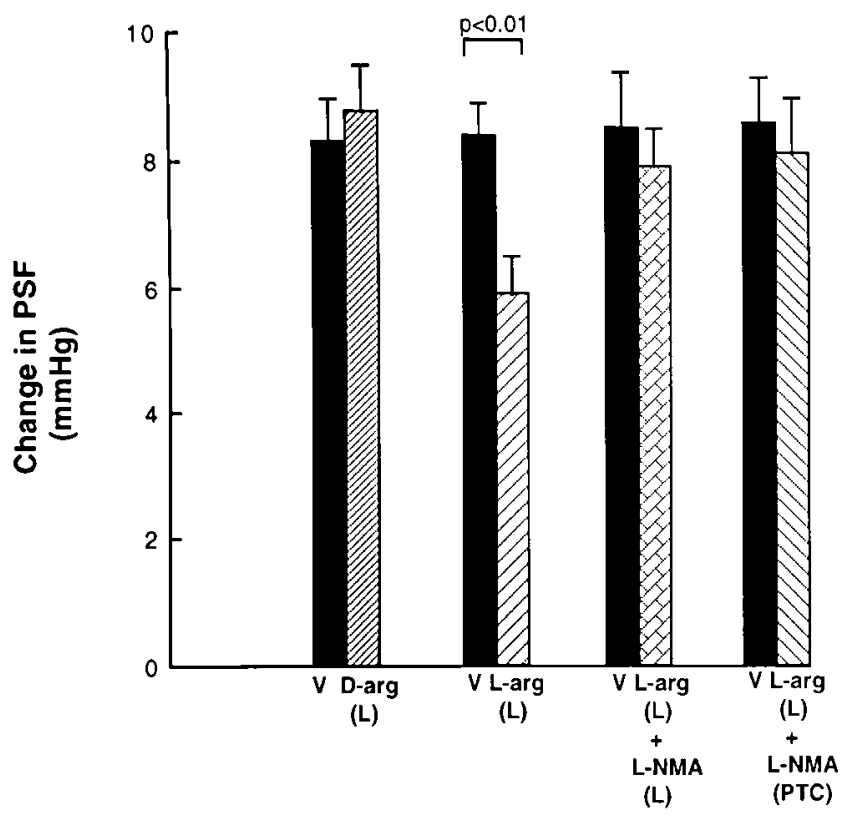

Figure 2. Maximal TGF responses as assessed from changes in PSF during orthograde loop $(L)$ perfusion with ATF at 0 and $40 \mathrm{nl} / \mathrm{min}$ in rats adapted to LS diet comparing ATF + vehicle (solid bars) and ATF with $10^{-3} \mathrm{M}$ solutions (cross-hatched bars) of the following: D-arginine $(n=12)$, L-arginine $(n=26), \mathrm{L}$-arginine coperfused with L-NMA $(n=12)$, or L-arginine with simultaneous PTC perfusion of L-NMA $(n=13)$. responses of nephrons of HS rats ( $\triangle \mathrm{PSF}$, before: $6.6 \pm 0.6 \mathrm{vs}$. during L-arginine: $7.0 \pm 0.4 \mathrm{mmHg} ; n=10$; NS). As shown in Fig. 3, during PTC microperfusion of L-arginine at the higher concentration of $10^{-3} \mathrm{M}$, maximal TGF responses were reduced in both the nephrons of LS ( $\triangle \mathrm{PSF}$, before: $9.2 \pm 0.5 \mathrm{vs}$. during L-arginine: $5.1 \pm 0.6 \mathrm{mmHg} ; n=8 ; P<0.01)$ and $\mathrm{HS}$ rats $(\triangle \mathrm{PSF}$, before: $6.5 \pm 0.5$ vs. during L-arginine: $4.8 \pm 0.4$ $\mathrm{mmHg} ; n=7 ; P<0.05)$. There was, however, a significantly greater percentage of blunting of TGF by arginine at both concentrations in LS rats when compared with HS rats (Fig. 3).

Studies were undertaken to test the hypothesis that the failure of L-NMA to enhance TGF responses in LS rat nephrons is due to limited NO generation because of deficient L-arginine availability. Luminal perfusion of L-NMA $\left(10^{-3} \mathrm{M}\right)$ enhanced maximal TGF responses in HS but not LS rat nephrons (Fig. 4), as reported previously (5). Peritubular capillary perfusion of L-arginine $\left(10^{-4} \mathrm{M}\right)$ again blunted maximal TGF responses in LS, but not HS rat nephrons. During PTC perfusion with L-arginine, however, luminal L-NMA enhanced TGF responses similarly in LS and HS rat nephrons. We conclude that the failure of L-NMA to enhance maximal TGF responses in LS rat nephrons can be corrected by local peritubular capillary perfusion of L-arginine.

An $\mathrm{A}_{1}$ AdoR antagonist was used to test the specificity of the effects of salt intake on the blunting of TGF by PTC perfusion of L-arginine. Fig. 5 compares changes in PSF produced by PTC perfusion of L-arginine $\left(10^{-4} \mathrm{M}\right)$ in $A$ with similar perfusions of CVT-124 $\left(10^{-3} \mathrm{M}\right)$ in $B$. The TGF responses to $\mathrm{LH}$ perfusion of ATF at $40 \mathrm{nl} / \mathrm{min}$ were blunted by PTC perfusion of CVT-124 in both LS rat nephrons $(8.7 \pm 0.7-7.2 \pm 0.6$; difference, $1.5 \pm 0.4 ; n=10 ; P<0.01)$ and $\mathrm{HS}$ rat nephrons (7.1 $\pm 0.5-5.9 \pm 0.4$; difference, $1.2 \pm 0.4 ; n=10 ; P<0.01)$. The percentage blunting of TGF by PTC CVT-124 was similar in LS $(-18 \pm 6 \%)$ and HS $(-16 \pm 5 \%)$. We conclude that the se-

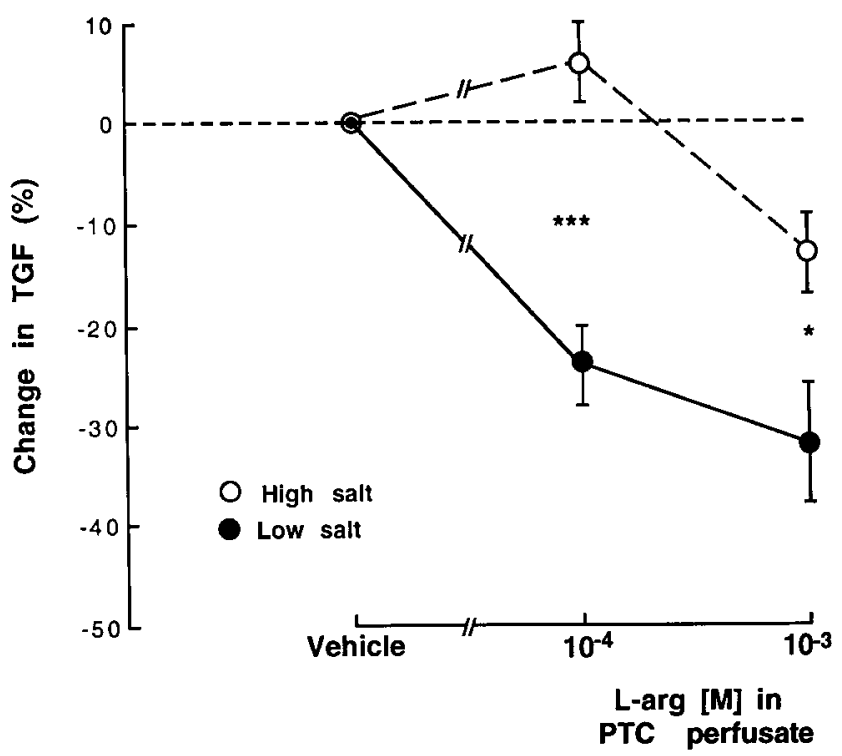

Figure 3. Percentage changes in maximal TGF responses, assessed from changes in PSF during orthograde loop perfusions of ATF at 0 and $40 \mathrm{nl} / \mathrm{min}$ in nephrons of rats adapted to low (solid symbols and continuous lines) or high (open symbols and broken lines) salt diets during PTC perfusions of L-arginine in artificial plasma at the concentrations shown. * $P<0.05 ; * * * P<0.005$. 

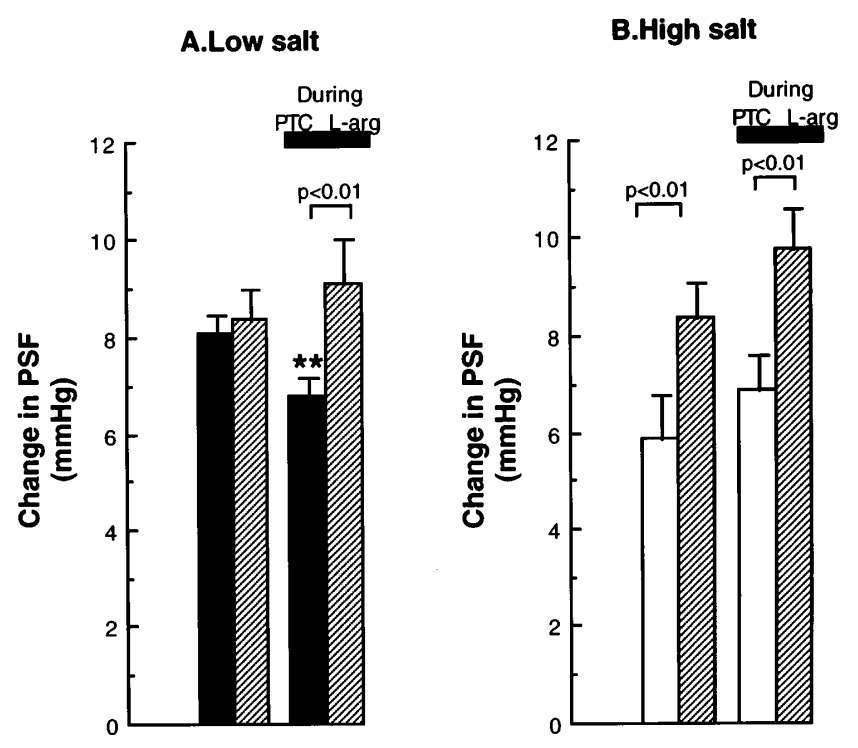

Table II. Changes in PSF Pressure During Orthograde Loop Perfusions of L-Arginine With or Without L-Lysine or L-Homoarginine: Effects of Salt Intake

\begin{tabular}{lcc}
\hline & \multicolumn{2}{c}{ Changes in PSF $(\mathrm{mmHg})$} \\
\cline { 2 - 3 } \multicolumn{1}{c}{ Addition to ATF } & LS & HS \\
\hline Series A & & \\
& $n=13$ & $n=9$ \\
Vehicle & $8.1 \pm 0.5$ & $5.1 \pm 0.4$ \\
L-arginine $\left(10^{-3} \mathrm{M}\right)$ & $5.9 \pm 0.7^{*}$ & $5.3 \pm 0.4$ \\
L-lysine $\left(2 \times 10^{-3} \mathrm{M}\right)$ & $7.9 \pm 0.6$ & $5.4 \pm 0.5$ \\
L-arginine $\left(10^{-3} \mathrm{M}\right)+$ L-lysine $\left(2 \times 10^{-3} \mathrm{M}\right)$ & $8.3 \pm 0.8^{\ddagger}$ & $5.1 \pm 0.5$
\end{tabular}

Series B

$\begin{array}{lll}\text { Vehicle } & 7.9 \pm 0.4 & 6.8 \pm 0.7 \\ \text { L-arginine }\left(10^{-3} \mathrm{M}\right) & 6.0 \pm 0.4^{*} & 6.2 \pm 0.6 \\ \text { L-homoarginine }\left(2 \times 10^{-3} \mathrm{M}\right) & 8.2 \pm 0.9 & 6.9 \pm 0.8 \\ \text { L-arginine }\left(10^{-3} \mathrm{M}\right)+\text { L-homoarginine } & 8.2 \pm 0.6^{\ddagger} & 6.8 \pm 0.6\end{array}$

Figure 4. Maximal TGF responses, assessed from changes in PSF during orthograde loop perfusion at 0 and $40 \mathrm{nl} / \mathrm{min}$ with artificial tubular fluid containing vehicle (solid and open boxes) or L-NMA $\left(10^{-3} \mathrm{M}\right.$; cross-hatched boxes). Data were obtained before or during peritubular capillary perfusion of L-arginine $\left(10^{-4} \mathrm{M}\right)$ in artificial plasma in groups of rats adapted to LS $(A)$ or HS $(B)$ intakes.

lective blunting of TGF by PTC L-arginine in LS rat nephrons is specific for L-arginine (Fig. $5 A$ ), and is not seen with a drug that blunts TGF by a different mechanism (Fig. $5 B$ ).

Series 4 examined the effects of coperfusion of L-arginine with a twofold excess of L-lysine or L-homoarginine that competes for system $\mathrm{y}^{+}$transport. As shown in Table II, compared to vehicle, addition of L-lysine or L-homoarginine to ATF perfused orthogradely into the LH did not alter PSF responses of nephrons of LS or HS rats. As in series 1, L-arginine dimin-

\section{A. PTC L-arginine}

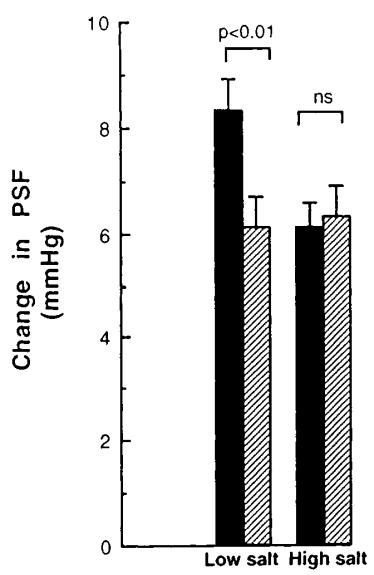

B. PTC CVT-124

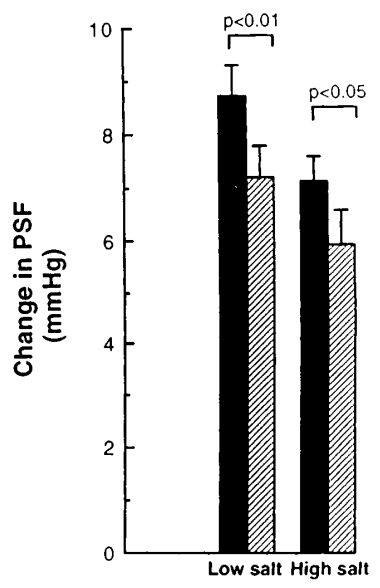

Figure 5. Maximal TGF responses as assessed from changes in PSF during orthograde loop perfusion with ATF at 0 and $40 \mathrm{nl} / \mathrm{min}$. Data shown are before (solid bars) and during (cross-hatched bars) peritubular capillary perfusion of $\mathrm{L}$-arginine $\left(10^{-4} \mathrm{M}\right.$ in AP) in $A$ or CVT$124\left(10^{-3} \mathrm{M}\right.$ in AP) in $B$ in nephrons of rats adapted to LS or HS intakes.

ished the maximal TGF responses of LS but not HS rat nephrons. Coperfusion of L-lysine or L-homoarginine with L-arginine fully blocked the effects of L-arginine in LS rat nephrons, but had no effect on the responses of HS rat nephrons where L-arginine itself was ineffective. These results are consistent with the hypothesis that the blunting of TGF responses by luminally delivered L-arginine in LS rat nephrons is dependent on L-arginine uptake via a system $\mathrm{y}^{+}$transporter.

For series 5, the effects of dietary salt intake on absorption of $\left[{ }^{3} \mathrm{H}\right] \mathrm{L}$-arginine from the perfused $\mathrm{LH}$ were studied. The loop was perfused from the LP at $20 \mathrm{nl} / \mathrm{min}$ with ATF $+\left[{ }^{3} \mathrm{H}\right] \mathrm{L}-$ arginine + amino acids. The early distal tubular fluid flow rate during loop perfusion with ATF + vehicle was $11.2 \pm 0.4 \mathrm{nl} / \mathrm{min}$ in LS rat nephrons, and was not significantly different at $12.6 \pm 0.7 \mathrm{nl} / \mathrm{min}$ in HS rat nephrons. None of the amino acids added to ATF perfusates altered the early distal tubular fluid flow rate significantly. Absorption of ${ }^{3} \mathrm{H}$ between the late proximal and early distal tubule was almost complete in nephrons from LS $(93 \pm 2 \%)$ and HS $(94 \pm 1 \%)$ rats, and was not significantly different in the two groups (Fig. 6). The results of studies in which competitors of system $\mathrm{y}^{+}$transport were perfused, however, indicate that salt intake modulates the L-arginine transport processes in the perfused LH. Coperfusion of $\left[{ }^{3} \mathrm{H}\right] \mathrm{L}$-arginine with L-glycine, which is not transported by a system $\mathrm{y}^{+}$process, led to a small but significant $(P<0.05)$ reduction in $\left[{ }^{3} \mathrm{H}\right]$ absorption compared with vehicle that was not significantly different in LS and HS rat nephrons. Coperfusion with an excess of unlabeled L-arginine significantly $(P<0.001)$ reduced absorption of the tracer from the LH (Fig. 6). This effect was significantly $(P<0.01)$ more pronounced in HS than in LS rat nephrons. Coperfusion with L-lysine or L-homoarginine both significantly $(P<0.01)$ blunted L-arginine reabsorption to a similar degree as excess L-arginine itself. Again, the effects of L-lysine and L-homoarginine to block ${ }^{3} \mathrm{H}$ absorption 


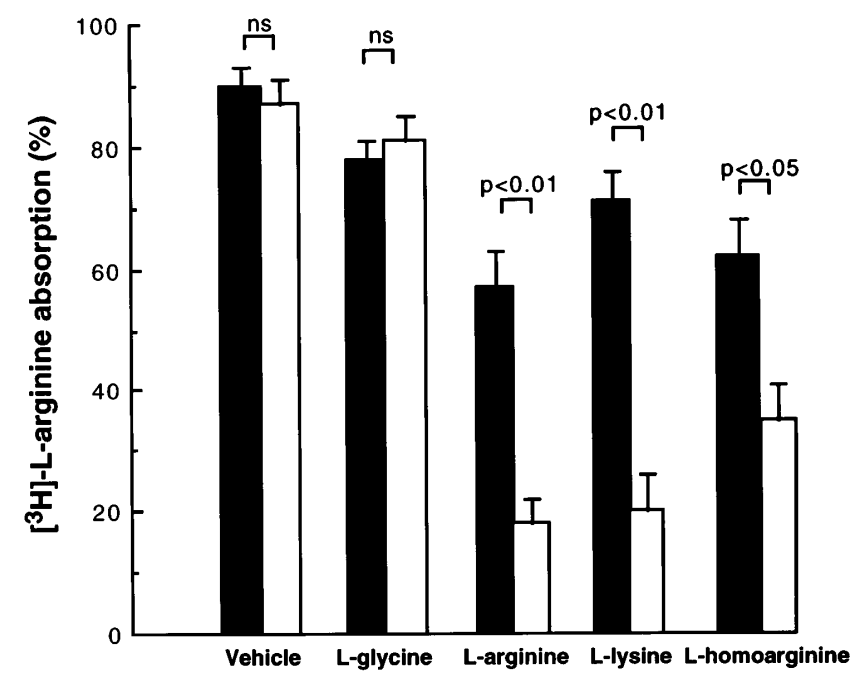

Figure 6. Absorbed $\left[{ }^{3} \mathrm{H}\right]$ during $\left[{ }^{3} \mathrm{H}\right] \mathrm{L}$-arginine perfusion into the late proximal tubule and collection from the early distal tubule of nephrons of LS (solid bars) and HS (open bars) rats, during addition to the artificial tubular fluid perfusate of vehicle (LS, $n=14$; HS, $n=21$ ), or $10^{-3} \mathrm{M}$ solutions of L-arginine ( $n=9$ in LS, and $n=9$ in HS), L-glycine (LS, $n=7$; HS, $n=7$ ), L-lysine (LS, $n=11$; HS, $n=10$ ), or L-homoarginine (LS, $n=10$; HS, $n=10$ ). Compared to vehicle, all amino acids added to ATF significantly $(P<0.05)$ reduced ${ }^{3} \mathrm{H}$ absorption. The $P$ values refer to comparison of data obtained in LS and HS rat nephrons.

from the loop segment were significantly $(P<0.05)$ greater in HS than in LS rat nephrons. We conclude that L-arginine is avidly absorbed from the perfused $\mathrm{LH}$ by a saturable process that depends upon transport by a pathway with the characteristics of system $\mathrm{y}^{+}$, and that this pathway is more active during HS than LS.

\section{Discussion}

We found previously that microperfusion of L-NMA into the MD segment enhances TGF responses of rats adapted to a high but not to a low salt intake (5). The main new findings of this study are that microperfusion of L-arginine, the substrate for NOS, into the MD segment blunts maximal TGF responses of rats adapted to a LS but not to a HS diet; this effect of L-arginine is stereospecific and is blocked by coperfusion with L-NMA. This result extends the findings of a recent study showing that luminal L-arginine blunts TGF responses of normal rats (6). Delivery of L-arginine by PTC perfusion causes dose-dependent blunting of maximal TGF responses; this effect is more sensitive in rats adapted to a LS compared to a HS intake. Microperfusion of L-arginine into the PTC adjacent to the test nephron restores a $\mathrm{P}_{\mathrm{GC}}$ response to luminal L-NMA in nephrons of LS rats, suggesting that the reason for the absent response to luminal L-NMA during LS intake is a limiting supply of L-arginine at the JGA. The blunting of TGF by luminal L-arginine in nephrons of LS rats is prevented by coperfusion with L-lysine or L-homoarginine that competes for system $\mathrm{y}^{+}$ transport. Reabsorption of microperfused $\left[{ }^{3} \mathrm{H}\right] \mathrm{L}$-arginine from the $\mathrm{LH}$ is blunted by coperfusion with excess L-arginine, L-lysine, or L-homoarginine, consistent with competition for a common $\mathrm{y}^{+}$transport process; this blunting is diminished in rats adapted to a LS intake, suggesting that $\mathrm{y}^{+}$transport of L-arginine out of the lumen of the $\mathrm{LH}$ is blunted during salt restriction. These results are consistent with the hypothesis that blunting of maximal TGF responses by NO generated in the JGA is limited during low salt intake by L-arginine delivery and/or uptake via a system $\mathrm{y}^{+}$transporter.

The effects of salt intake on the response to L-arginine did not appear to be secondary to differences in the baseline TGF responses or the degree of vasodilatation of the afferent arteriole. Thus, an $\mathrm{A}_{1} \mathrm{AdoR}$ antagonist that induces NO-independent afferent arteriolar vasodilation (22), when infused into the interstitium, blunted TGF in LS rats to a similar degree as it did in HS rats.

Infusions of large quantities of L-lysine cause tubular damage and renal failure in the rat. This effect, which seems specific for L-lysine (23), requires infusion of $\sim 400-1,000 \mathrm{mg} / \mathrm{kg}$ over 45-90 min (24). A tubular toxic response to L-lysine does not appear to explain our results since the brief (4-min) intratubular perfusions of L-lysine given alone did not alter tubular fluid reabsorption in the perfused loop or TGF responses, and L-homoarginine, which is also a substrate for system $\mathrm{y}^{+}$ but is not known to be toxic (25), was equally effective.

TGF is activated by reabsorption of $\mathrm{NaCl}$ at the MD segment with subsequent vasoconstriction of the afferent arteriole and reduction of $\mathrm{P}_{\mathrm{GC}}$ and single nephron GFR. Blunting of TGF during a HS intake may be important to body fluid homeostasis by permitting ongoing delivery of $\mathrm{NaCl}$ to the $\mathrm{MD}$ and distal nephron without curtailing renal blood flow or GFR. Previous studies have implicated the renin-angiotensin system (1) and thromboxane $A_{2}$ (26) in addition to L-arginine-derived NO (5) in adapting TGF to changes in salt intake.

Perfusion of L-NMA into the MD enhances maximal TGF responses in rats adapted to normal or HS, but not LS intakes (5). The absence of a response to NOS blockade during salt restriction cannot be ascribed to a failure to express nNOS in the MD because its immunocytochemical expression $(8,9)$ and mRNA abundance (10) in the MD is enhanced during salt restriction $(8,9)$. This finding that MD perfusion of L-arginine causes a robust NOS-dependent blunting of TGF in nephrons of salt-restricted rats demonstrates that the NOS expressed in the JGA during salt restriction is biologically active.

It is possible that the effects of luminal L-arginine or L-NMA on TGF responses in these protocols are due to NO generation at extratubular sites, since inducible NOS is expressed in the afferent arterioles and mesangial cells (3) and endothelial NOS in the microvascular endothelium (4). Previous studies in an isolated, perfused rabbit JGA preparation, however, have shown that luminally perfused nitro-L-arginine enhances TGF without impairing the vasodilator response to acetylcholine perfused into the afferent arteriole (27). Moreover, TGF responses are enhanced during luminal perfusion of 7-nitroindazole, which is a relatively selective inhibitor of nNOS (6). These observations, coupled with the dense expression of nNOS in the $\mathrm{MD}$, make it likely that this is the major source of changes in juxtaglomerular NO generation during luminal perfusion with L-arginine or L-NMA. PTC perfusion of L-arginine presumably has an additional site of action on TGF compared to luminal L-arginine because, unlike luminal delivery, there was blunting of TGF responses by the higher concentration of L-arginine in rats adapted to a HS diet, albeit not to the extent of salt-restricted rats. L-arginine delivered via this route may have direct access to iNOS in afferent arterioles (3) or eNOS in vascular endothelium (4). 
L-arginine is an absolute requirement for $\mathrm{NO}$ generation by NOS in cultural endothelial cells or blood vessel wall (14, 28). Intracellular L-arginine levels in cultured endothelial cells, however, are normally well above the $K_{\mathrm{m}}$ for NOS (29), and these cells can maintain their intracellular L-arginine concentration for up to $2 \mathrm{~h}$ during incubation in an arginine-free solution (28). Thus, L-arginine should not normally be rate-limiting for NO generation. Endothelial cell NO generation, however, is inhibited by asymmetric dimethylarginine (ADMA) (30). This inhibition can be overcome by increasing $\mathrm{L}$-arginine in a physiologically relevant concentration range (30). Thus, the effective $K_{\mathrm{m}}$ for NOS in vivo may be higher than in purified systems. The kidney can generate mono- and dimethylarginines, and the enzyme $\mathrm{N}^{\mathrm{G}}, \mathrm{N}^{\mathrm{G}}$-dimethyarginine demethylaminohydrolase, which metabolizes methylarginines to L-citrulline, is expressed in the MD (31). MD NOS is inhibited by luminal perfusion of ADMA, and $\mathrm{LH}\left[{ }^{3} \mathrm{H}\right] \mathrm{L}$-arginine uptake is inhibited by ADMA and symmetric dimethylarginine (31). Therefore, MD uptake of L-arginine and nNOS activity may be tonically inhibited, thereby accounting for a requirement for excess L-arginine to fully activate NO generation during LS.

Arginine uptake by tubule cells is largely carrier-mediated $(17,18,32)$. System $\mathrm{y}^{+}$is Na-independent and transports L-arginine, L-lysine, L-homoarginine, and L-ornithine competitively (14-16). The finding that the effects of luminal perfusion of L-arginine on TGF responses are stereospecific and are blocked by coperfusion with an excess of L-lysine or L-homoarginine indicates that MD cells also contain a luminal system $\mathrm{y}^{+}$transporter. TGF responses were not blunted by L-lysine or L-homoarginine perfused alone, perhaps because they were perfused only $4 \mathrm{~min}$, a time that was likely insufficient to exhaust cellular arginine stores.

$\left[{ }^{3} \mathrm{H}\right] \mathrm{L}$-arginine was almost completely reabsorbed by the perfused LH. This segment contains a heterogeneous group of cells that likely differ in their L-arginine transport characteristics. Basic amino acid transport in the kidney has been studied extensively by Silbernagl, Dantzler, and colleagues $(17,18,25$, $32,33)$. Reabsorptive flux of amino acids from the LH cannot be accounted for by passive diffusion (25), and is independent of $\mathrm{NaCl}$ reabsorption since it is not inhibited by furosemide (33). Our results confirm the findings of Silbernagl et al., that fractional absorption of tracer concentrations of labeled L-arginine from the perfused LH exceed $85 \%$ (18), are saturable, and are inhibited by L-homoarginine $(18,25)$. In our studies, L-lysine was as effective as L-homoarginine in competing for $\left[{ }^{3} \mathrm{H}\right] \mathrm{L}$-arginine absorptive flux consistent with a system $\mathrm{y}^{+}$carrier (14-16). Dantzler and Silbernagl (25), however, concluded that the reabsorption of L-lysine was quite nonspecific. It is possible that the 25-fold higher concentrations of L-lysine used in the previous study may have interfered with tubular function (23). The differences, however, may also relate to the age and strain of rat used (Dantzler and Silbernagl [25] studied 113-g Wistar rats), or to the preparation since, as we found in this study, dietary salt intake has profound effects on the $\left[{ }^{3} \mathrm{H}\right] \mathrm{L}$-arginine absorptive flux. Additionally, Dantzler and Silbernagl (25) have shown further that $36 \%$ of L-arginine microperfused into the ascending vasa recta is transferred into the ascending limbs of the LH by a saturable transport process. Thus, L-arginine can be supplied to the tubular lumen of the LH despite almost complete proximal reabsorption (32), thereby accounting for the higher levels in the distal tubule (18).

Overall, the rate of $\left[{ }^{3} \mathrm{H}\right] \mathrm{L}$-arginine absorption from the per- fused loops was similar in rats adapted to LH or HS intakes, and was nearly complete, demonstrating that this nephron segment has avid L-arginine transport. The much greater blockade of $\left[{ }^{3} \mathrm{H}\right] \mathrm{L}$-arginine absorption during coperfusion with excess L-arginine, L-lysine, or L-homoarginine, however, that compete for system $\mathrm{y}^{+}$transport, demonstrates considerable effects of salt intake on cationic amino acid transport from the perfused loop segment. During salt restriction, there was less inhibition of ${ }^{3} \mathrm{H}$ absorption by the competing amino acids, indicating less saturable absorptive flux of $\left[{ }^{3} \mathrm{H}\right] \mathrm{L}$-arginine via system $\mathrm{y}^{+}$transport. There was a similar (and relatively small) inhibition by L-glycine that does not compete for this transport process. Presumably, decreased system $\mathrm{y}^{+}$transport out of the LH during salt restriction can be offset by increased L-arginine transport by another process. Indeed, in previous studies in the papilla, L-arginine was shown to be absorbed by a system $\mathrm{y}^{+}$independent mechanism (25).

L-arginine is filtered at the glomerulus, extensively reabsorbed in the proximal tubule (32), transported into and out of the LH (25), and is generated from L-citrulline (34) and metabolized by arginase to L-ornithine and urea (35) or arginine decarboxylase to agmatine (36), or by methylases to methylated arginine derivatives (30) in endothelial or proximal tubule cells. Therefore, it is hard to predict its luminal or renal interstitial concentrations. Salt restriction in the rat reduces the plasma arginine concentrations by $50 \%$, but increases plasma ornithine (13) and urea appearance (37), indicating an increased flux of arginine through arginase. Infusion of L-arginine into peritubular capillary blood at a concentration calculated to restore the PTC plasma level of L-arginine in LS rats approximately to levels in $\mathrm{HS}$ rats restored the $\mathrm{P}_{\mathrm{GC}}$ response to NOS blockade with luminal L-NMA. This result was quite surprising, given that L-arginine formed in proximal tubules must presumably increase renal cortical interstitial levels, and that the peritubular capillaries supply many structures in addition to the MD. Nevertheless, this finding suggests that physiologically relevant changes in L-arginine delivery or uptake via system $\mathrm{y}^{+}$may account for alterations in NO generation in the JGA. Apparently, NO generation in the JGA may be regulated not only by changes in cell calcium concentration or NOS expression, but also by L-arginine availability.

\section{Acknowledgments}

We are grateful to Marly Davidson for typing the manuscript.

This work was supported by grants from the National Institutes of Diabetes, Digestive and Kidney Diseases (DK 49870 and DK 36079) and the National Kidney Foundation, Capitol Affiliate, and by funds from the George F. Schreiner Chair of Nephrology.

\section{References}

1. Briggs, J.P., and J. Schnermann. 1995. Control of renin release and glomerular vascular tone by the juxtaglomerular apparatus. In Hypertension: Pathophysiology, Diagnosis, and Management. J.H. Laragh and B.M. Brenner, editors. Raven Press, Ltd., New York. 1359-1384.

2. Wilcox, C.S., W.J. Welch, F. Murad, S.S. Gross, G. Taylor, R. Levi, and H.H.H.L. Schmidt. 1992. Nitric oxide synthase in macula densa regulates glomerular capillary pressure. Proc. Natl. Acad. Sci. USA 89:11993-11997.

3. Tojo, A., L. Zhang, C.S. Wilcox, W.J. Welch, C.C. Tisher, K.M. Madsen, S.S. Gross, and H.H.H.W. Schmidt. 1992. Differential localization and regulation of nitric oxide synthase isoforms in the juxtaglomerular apparatus. J. Am. Soc. Nephrol. 3:554(Abstr.).

4. Bachmann, S., H.M. Bosse, and P. Mundel. 1995. Topography of nitric oxide synthesis by localizing constitutive NO synthases in mammalian kidney. Am. J. Physiol. 268 (5 pt. 2):F885-F898. 
5. Wilcox, C.S. and W.J. Welch. 1996. TGF and nitric oxide: effects of salt intake and salt-sensitive hypertension. Kidney Int. 49(Suppl. 55):S9-S13.

6. Thorup, C., and A.E.G. Persson. 1996. Macula densa derived nitric oxide in regulation of glomerular capillary pressure. Kidney Int. 49:430-436.

7. Welch, W.J., and C.S. Wilcox. 1993. Independent effects of salt intake and angiotensin II on the macula densa-nitric oxide signalling pathway. J. Am. Soc. Nephrol. 4:572(Abstr.).

8. Bosse, H.M., R. Bohm, S. Resch, and S. Bachmann. 1995. Parallel regulation of constitutive NO synthase and renin at JGA of rat kidney under various stimuli. Am. J. Physiol. 269(6 pt. 2):F793-F805.

9. Tojo, A., K.M. Madsen, and C.S. Wilcox. 1995. Expression of immunoreactive nitric oxide synthase isoforms in rat kidney: effects of dietary salt and losartan. Jpn. Heart J. 36:389-398.

10. Singh, I., M. Grams, W.-H. Wang, T. Yang, P. Killen, A. Smart, J. Schnermann, and J.P. Briggs. 1996. Coordinate regulation of renal expression of nitric oxide synthase, renin, and angiotensinogen mRNA by dietary salt. Am. J. Physiol. 270 (6 pt. 2):F1027-F1037.

11. He, X.R., S.G. Greenberg, J.P. Briggs, and J. Schnermann. 1995. Effects of furosemide and verapamil on the $\mathrm{NaCl}$ dependency of macula densa-mediated renin secretion. Hypertension (NY). 26:137-142.

12. Deng, X., W.J. Welch, and C.S. Wilcox. 1995. Renal vasodilation with L-arginine: effects of dietary salt. Hypertension (NY). 26:252-262.

13. Deng, X., W.J. Welch, and C.S. Wilcox. 1995. Plasma arginine concentration and renal nitric oxide generation during changes in dietary salt and angiotensin II. J. Amer. Soc. Nephrol. 6:658(Abstr.).

14. Schmidt, H.H.H.W., S.E. Baeblich, B.C. Zernikow, M.M. Klein, and E. Bohme. 1990. L-arginine and arginine analogues: effects on isolated blood vessels and cultured endothelial cells. Br. J. Pharmacol. 101:145-151.

15. Schmidt, K., P. Klatt, and B. Mayer. 1993. Characterization of endothelial cell amino acid transport systems involved in the actions of nitric oxide synthase inhibitors. Mol. Pharmacol. 44:615-621.

16. Schmidt, K., B.M. List, P. Klatt, and B. Mayer. 1995. Characterization of neuronal amino acid transporters: uptake of nitric oxide synthase inhibitors and implication for their biological effects. J. Neurochem. 64:1469-1475.

17. Dantzler, W.H., and S. Silbernagl. 1988. Amino acid transport by juxtamedullary nephrons: Distal reabsorption and recycling. Am. J. Physiol. 255: F397-F407.

18. Silbernagl, S., K. Volker, and W.H. Dantzler. 1994. Cationic amino acid fluxes beyond the proximal convoluted tubule of rat kidney. Pflügers Arch. 429: 210-215.

19. Welch, W.J., and C.S. Wilcox. 1992. Potentiation of tubuloglomerular feedback in the rat by thromboxane mimetic. Role of macula densa. J. Clin. Invest. 89:1857-1865.

20. Bellardinelli, L., J.C. Shryock, Y. Zhang, P.J. Scammells, R. Olsson, D. Dennis, P. Milner, J. Pfister, and S.P. Baker. 1995. 1,3-dipropyl-8-[2-(5,6-epoxy)norbornyl xanthine, a potent, specific and selective $\mathrm{A}_{1}$ adenosine receptor antagonist in the guinea pig heart and brain and in DDT $_{1}$ MF-2 cells. J. Pharmacol. Exp. Ther. 275:1167-1176.

21. Welch, W.J., G.F. Schreiner, L. Belardinelli, and C.S. Wilcox. 1996. Natriuretic response to A1 adenosine receptor blockade: Roles of proximal reabsorption and tubuloglomerular feedback. J. Am. Soc. Nephrol. 7:1544(Ab- str.).

22. Ren, Y.L., and S. Ito. 1994. Adenosine (Ado) modulates macula densa (MD) control of afferent arteriolar (Af-Art) resistance. J. Am. Soc. Nephrol. 5: 610(Abstr.)

23. Racusen, L.C., A. Whelton, and K. Solez. 1985. Effects of lysine and other amino acids on kidney structure and function in the rat. Am. J. Pathol. 120:436-442.

24. Racusen, L.C., W.F. Finn, A. Whelton, and K. Solez. 1985. Mechanisms of lysine-induced acute renal failure in rats. Kidney Int. 27:517-522.

25. Dantzler, W.H., and S. Silbernagl. 1993. Basic amino acid transport in renal papilla: Microinfusion of Henle's loops and vasa recta. Am. J. Physiol. 265:F830-F838.

26. Welch, W.J., and C.S. Wilcox. 1992. Modulation of TG feedback by thromboxane: Effects of dietary salt and angiotensin. J. Am. Soc. Nephrol. 3 : 571(Abstr.).

27. Ito, S., and Y. Ren. 1993. Evidence for the role of nitric oxide in macula densa control of glomerular hemodynamics. J. Clin. Invest. 92:1093-1098.

28. Mitchell, J.A., M. Hecker, E.E. Anggard, and J.R. Vane. 1990. Cultured endothelial cells maintain their L-arginine level despite the continuous release of EDRF. Eur. J. Pharmacol. 182:573-576.

29. Arnal, J.F. T. Munzel, R.C. Venema, N.L. James, C. Bai, and W.E. Mitch. 1995. Interactions between L-arginine and L-glutamine change endothelial NO production. An effect independent of NO synthase substrate availability. J. Clin. Invest. 95:2565-2572.

30. MacAllister, R.J., S.A. Fickling, G.S.J. Whitley, and P. Vallance. 1994. Metabolism of methylarginines by human vasculature: Implications for the regulation of nitric oxide synthesis. Br. J. Pharmacol. 112:43-48.

31. Tojo, A., C.S. Wilcox, V. Bremer, M. Kimoto, W.J. Welch, K. Kimuru, M. Omata, T. Ogawa, and P. Vallance. 1996. Methyl arginines in rat kidney: comparison of immunohistochemical localization of demethylating enzyme $\mathrm{N}^{\mathrm{G}}$, $\mathrm{N}^{\mathrm{G}}$-dimethylarginine dimethylaminohydrolase (DDAH) with nitric oxide synthase, and effects on arginine transport. J. Am. Soc. Nephrol. 7:1574(Abstr.)

32. Silbernagl, S., and P. Deetjen. 1973. Molecular specificity of the L-arginine reabsorption mechanism. Microperfusion studies in the proximal tubule of rat kidney. Pflügers Arch. 340:325-334.

33. Dantzler, W.H., and S. Silbernagl. 1991. Specificity of amino acid transport in renal papilla: microinfusion of Henle's loops and vasa recta. Am. J. Physiol. 261:F495-F504.

34. Levillain, O., A. Hus-Citharel, F. Morel, and L. Bankir. 1993. Arginine synthesis in mouse and rabbit nephron: localization and functional significance. Am. J. Physiol. 264(6 pt. 2):F1038-F1045.

35. Levillain, O., A. Hus-Citharel, F. Morel, and L. Bankir. 1992. Localization of urea and ornithine production along mouse and rabbit nephrons: functional significance. Am. J. Physiol. 263(5 pt. 2):F878-F885.

36. Lortie, M.J., W.F. Novotny, O.W. Peterson, V. Vailon, K. Malvey, M. Mendonca, J. Satriano, P. Insel, S.C. Thomson, and R.C. Blantz. 1996. Agmatine, a bioactive metabolite of arginine. Production, degradation and functional effects in the kidney of the rat. J. Clin. Invest. 97:413-420.

37. Kamm, D.E., L. Wu, and B.L. Kuchmy. 1987. Contribution of the urea appearance rate to diuretic-induced azotemia in the rat. Kidney Int. 32:47-56. 